UDC 811.112.2' $42: 61$

Submitted: 23.01.2017

LBC 81.432.4-51

Accepted: 28.04.2017

\title{
GERMAN POPULAR SCIENTIFIC MEDICAL ONLINE MEDIA: STRUCTURAL AND FUNCTIONAL ASPECTS
}

\author{
Nikolay L. Shamne \\ Volgograd State University, Volgograd, Russian Federation \\ Ekaterina V. Shishkina \\ Volgograd State Medical University, Volgograd, Russian Federation
}

\begin{abstract}
The relevance of the study is determined by formation of self-treatment and self-diagnostic as the leading trends in modern healthcare in many countries. This fact is confirmed by the increase of the number of search queries with the semantic core of "health" in the global network. The object of research in the article are German-language medical popular scientific Internet publications that are studied in the aspect of structuring their textual content and realizable functions. The Internet edition is defined as a virtual resource with media functions. Structural features of the Internet publication are identified: additional content, the vastness of the whole functionalthematic block, the relationship of texts through active links, more illustrated material, interactivity. Functionalthematic blocks of 40 editions are examined in detail in the article, a set of frequency units (food, health, sports, psyche, illness) and unique sections are established. Based on the classifications of communicative functions proposed in linguistics, the relevant functions in medical popular science discourse are revealed: information, advice, warning, entertainment, refutation, advertising. It was established that the information function is realized in all texts of the discourse, but its status (basic or auxiliary) varies depending on the target settings of the text. This research will open possibilities for further study of the medical science popular discourse by considering pragmatic and stylistic aspects.

Key words: functional and thematic unit, online media, medical discourse, popular scientific discourse, German language, health, function of the text.

Citation. Shamne N.L., Shishkina E.V. German Popular Scientific Medical Online Media: Structural and Functional Aspects. Vestnik Volgogradskogo gosudarstvennogo universiteta. Seriya 2, Yazykoznanie [Science Journal of Volgograd State University. Linguistics], 2017, vol. 16, no. 2, pp. 143-151. (in Russian). DOI: https://doi.org/10.15688/jvolsu2.2017.2.15.
\end{abstract}

\section{НАУЧНО-ПОПУЛЯРНЫЕ МЕДИЦИНСКИЕ ИНТЕРНЕТ-ИЗДАНИЯ НА НЕМЕЦКОМ ЯЗЫКЕ: СТРУКТУРНЫЙ И ФУНКЦИОНАЛЬНЫЙ АСПЕКТЫ}

\author{
Николай Леонидович Шамне \\ Волгоградский государственный университет, г. Волгоград, Российская Федерация \\ Екатерина Викторовна Шишкина
}

Волгоградский государственный медицинский университет, г. Волгоград, Российская Федерация

Аннотация. Актуальность исследования обусловливается становлением самолечения и самодиагностики в качестве ведущих тенденций в современном здравоохранении многих стран, что подтверждается увеличе- 
нием количества поисковых запросов с семантическим ядром «здоровье» в глобальной сети. Объектом исследования в статье избраны немецкоязычные медицинские научно-популярные интернет-издания в аспекте структурирования их текстового наполнения и реализуемых функций. Интернет-издание определено как виртуальный ресурс с функциями СМИ. Выявлены его структурные признаки: дополнительный контент, необозримость целого функционально-тематического блока, взаимосвязь текстов через активные ссылки, более иллюстрированный материал, интерактивность. Детально описаны функционально-тематические блоки 40 изданий, установлены частотные (питание, здоровье, спорт, психика, заболевания) и уникальные разделы. На основе предложенных в лингвистике классификаций коммуникативных функций выявлены релевантные функции, присущие медицинскому научно-популярному дискурсу: информация, совет, предупреждение, развлечение, опровержение, реклама. Установлено, что функция информирования реализуется во всех текстах данного дискурса, однако ее статус (базовая или вспомогательная) варьируется в зависимости от целевых установок текста. Результаты исследования доказывают необходимость расширения рамок изучения медицинского научно-популярного дискурса за счет рассмотрения его в лингвопрагматическом и стилистическом аспектах.

Ключевые слова: функционально-тематический блок, интернет-издание, медицинский дискурс, научно-популярный дискурс, немецкий язык, здоровье, функция текста.

Цитирование. Шамне Н. Л., Шишкина Е. В. Научно-популярные медицинские интернет-издания на немецком языке: структурный и функциональный аспекты // Вестник Волгоградского государственного университета. Серия 2, Языкознание. - 2017. - Т. 16, № 2. - C. 143-151. - DOI: https://doi.org/10.15688/ jvolsu2.2017.2.15.

1

Востребованность в социуме научно-популярных медицинских интернет-изданий и возрастание роли медицинского научно-популярного дискурса обусловлены тенденциями к самодиагностике и самолечению, которые становятся ведущими в здравоохранении многих стран мира. Медицинская грамотность населения растет. Наиболее частыми поисковыми запросами в глобальной сети являются запросы о здоровье (симптомах болезней, профилактике, возможностях лечения). Так, в 2005 г. информацию, относящуюся к здоровью, искали 117 миллионов пользователей; в 2006 г. их количество возросло на $16 \%$, а в 2016 г. - превысило миллиард (см. статистику поисковых запросов на уandex.ru и google.com). Благодаря новейшим информационным технологиям массовому потребителю стали доступны приложения для осуществления самодиагностики, подробная информация о различных заболеваниях, медицинская техника; пользователи самостоятельно читают результаты анализов, обмениваются опытом на соответствующих интернет-форумах.

Среди факторов, стимулирующих пользователей искать медицинскую информацию в Интернете, можно выделить следующие:

- увеличение стоимости медицинской страховки;

- высокая стоимость визита к врачу;

- снижение качества медицинских услуг;
- появление в свободной продаже медицинских инструментов для самодиагностики и самолечения;

- продажа лекарственных средств без рецепта;

- страх пациента перед новыми лекарственными средствами;

- отсутствие доверия к лечащему врачу;

- наличие в Интернете большого количества разнообразной медицинской информации.

Учитывая названные факторы, человек делает выбор в пользу самоконтроля и собственной ответственности за свое здоровье, предъявляя высокие требования к качеству медицинской информации, представленной в том или ином издании. Оно обеспечивается и языковой составляющей, что обусловило необходимость лингвистического структурно-содержательного анализа интернет-изданий как наиболее доступных массовому читателю. Несмотря на неослабевающий научный интерес лингвистов к медицинскому дискурсу (см. например, работы последних лет: [Ахнина, 2016; Ахнина, Куриленко, 2015; Гагарина, 2016; Макушева, Ковалева, 2014]), немецкоязычные научно-популярные интернет-издания еще не были объектом специального изучения.

2

В центре нашего внимания находятся немецкоязычные интернет-издания, посвящен- 
Н.Л. Шамне, Е.В. Шишкина. Научно-популярные медицинские интернет-издания на немецком языке

ные здоровью и медицине. Материалом для исследования послужили 40 научно-популярных интернет-изданий, часть из которых имеет печатные аналоги ${ }^{1}$. Интернет-издание представляет собой виртуальный ресурс с функциями СМИ, содержащий актуальные сведения публицистического характера. По тематической наполненности интернет-издание частично или полностью соответствует печатной версии. Отличительными структурными особенностями интернет-издания являются:

- дополнительный контент (аудио- и видеоматериалы, приложения, тесты, ссылки);

- необозримость целого тематического блока (список рубрик, заглавия и аннотации наиболее популярных статей);

- взаимосвязь текстов через активные ссылки;

- более иллюстрированный материал (адресат взаимодействует с информацией с помощью вербальных и невербальных средств);

- интерактивность (возможность оценить статью, распространить информацию через аккаунт в социальной сети, обсудить ее в онлайн-конференции, подписаться на издание, перейти на сайт рекламируемого товара, заказать товары и услуги).
В качестве примера охарактеризуем интернет-сайт издания «Apotheken Umschau», который имеет печатную версию.

В левом верхнем углу главной страницы сайта (рис. 1) указано наименование журнала и его знак - красная готическая буква «А» древним символом врачевания и исцеления фармацевтической чашей и змеей. В правом верхнем углу страницы расположены иконки социальных сетей, нажав на которые можно поделиться информацией или подписаться на новостные обновления. Ниже пользователю доступна строка поиска, где по ключевому слову можно найти необходимую информацию. По центру располагаются тематические блоки, которые остаются неизменными от номера к номеру: Startseite (Главная страница), Krankheiten (Заболевания), Symptome (Симптомы), Medikamente (Медикаменты), Diagnostik und Therapie (Диагностика и терапия), Ernährung (Питание), Sport (Спорт), Psyche (Психика). Текстовое наполнение этих категорий обновляется еженедельно. Устаревшие статьи переносятся в архив. На главной странице представлен и дополнительный контент - видео, тесты, игры, специальные приложения, а также перечень домов преста-

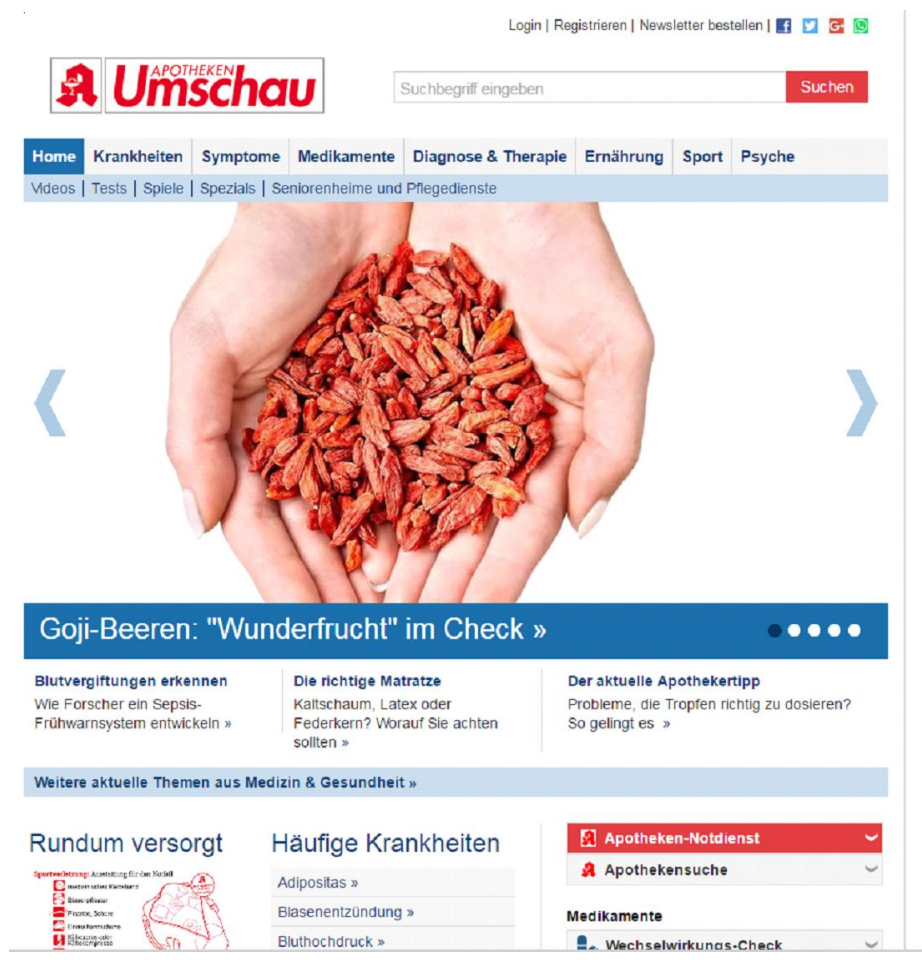

Рис. 1. Главная страница сайта издания «Apotheken Umschau» 
релых и служб по уходу за больными. По центру страницы в быстром доступе транслируются заглавия пяти наиболее актуальных статей. Ниже приведены аннотации имеющихся в номере сообщений, параметры поиска ближайшей аптеки, инструкции к медицинскому препарату, печатная версия номера.

Структура данного интернет-издания во многом схожа со структурами других изданий той же направленности, отличия наблюдаются в дизайнерских решениях, верстке, наборе функционально-тематических блоков.

\section{3}

В данной статье под функционально-тематическим блоком понимается совокупность текстов, выделяемая на основе общего семантического ядра, характеризующаяся содержательно-тематическим единством и доминированием той или иной релевантной текстовой функции ${ }^{2}$.

Анализ материала позволил установить общие и уникальные функционально-тематические блоки. Количественная характеристика общих блоков представлена на диаграмме (рис. 2).

Как свидетельствует диаграмма, $90 \%$ изданий включают блок Ernährung / Essen (Питание). В качестве самостоятельных рубрик этого блока читателю доступны Rezepte (Рецепты), Diät (Диета), Abnehmen / Gesundes Gewicht (Похудение / Здоровый вес).
Блок Gesundheit (Здоровье) включает 85 \% изданий, блоки Sport / Bewegung / Körper / Fitness (Спорт / Движение / Тело / Фитнес) $80 \%$. Заглавия отличаются в зависимости от издания, однако схожесть текстового наполнения дает нам основание считать их одним функционально-тематическим блоком.

Частотный блок Psyche (Психика) встречается в $64 \%$ научно-популярных медицинских изданий. Часть изданий (62 \%) включают постоянный блок под названием Krankheiten (Заболевания) с большим количеством рубрик: Krankheiten von $A-Z$ (Заболевания от А до Я); Allergien (Аллергии); Augen (Глаза); Diabetes (Диабет); Fusspilz (Грибок стопы); Gastroenterologie (Гастроэнтерология); Haut (Кожа); Krebs und Onkologie (Рак и онкология); Niere und Dialyse (Почки и диализ); Psychische Krankheiten / Seele (Психические заболевания / Душа); Schmerzen (Боли); Atmung / Lunge (Дыхание / Легкие); Frauenheilkunde (Гинекология); Hals, Nase, Ohren (Ухо, Горло, Нос); Immunsystem / Infektionskrankheiten (Иммунная система / Инфекционные заболевания); Knochen / Muskeln (Кости / Мышцы); Kreislauf / Herz (Кровообращение / Сердце); Nervensystem (Нервная система); Stoffwechsel (Обмен веществ); Urologie (Урология).

Около половины анализируемых изданий (53\%) предлагают вниманию читателя блок Symptome / Diagnose (Симптомы / Диагноз). Весьма популярны также блоки с семантичес-

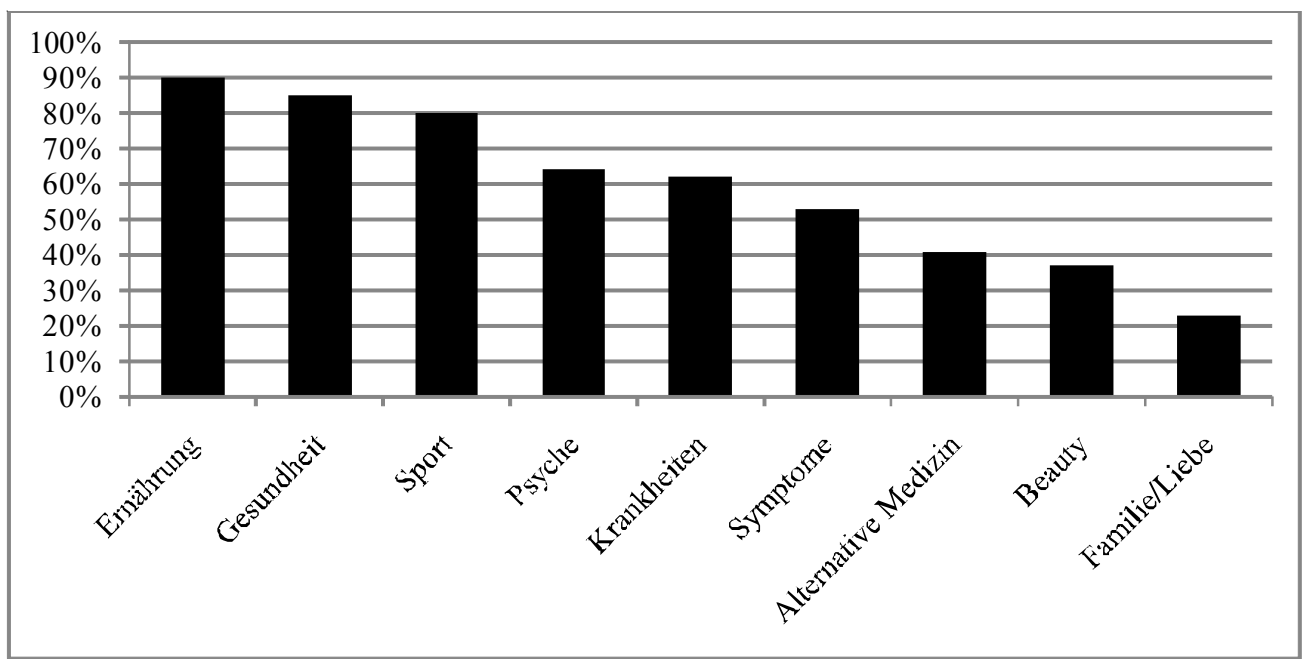

Рис. 2. Частотные функционально-тематические блоки медицинских научно-популярных интернет-изданий на немецком языке 
Н.Л. Шамне, Е.В. Шишкина. Научно-популярные медицинские интернет-издания на немецком языке

ким ядром Alternative Medizin (41\%) и рубриками Heilpflanzen / Pflanzenheilkunde (Лекарственные растения / Фитотерапия); Homöopathie (Гомеопатия); Kinesiologie (Кинезиология); Naturheilkunde (Натуропатия); Osteopathie (Остеопатия), а также блок Beauty (Красота) - 37 \% - с рубриками Naturkosmetik (Натуральная косметика); Kosmetik (Косметика); Hautpflege (Уход за кожей); Pflege (Уход); Schönheit (Красота).

В ходе исследования были установлены уникальные для рассматриваемых изданий функционально-тематические блоки: Stress / Soziales Stress (Стресс / Социальный стресс); Vorsorge (Профилактика); Junge Familie / Liebe \& Familie / Liebe \& Sex (Молодая семья / Любовь \& Семья / Любовь \& Секс); Senioren / Rentner (Пожилые люди / Пенсионеры); Rauchentwöhnung (Избавление от табакозависимости); Reisen \& Erholen / Reisen \& Wohlfühlen (Путешествие \& Отдых / Путешествие \& Комфорт); Schwangerschaft / Baby (Беременность / Младенец); Teenager (Подросток); Hausmittel (Домашние средства); Tiergesundheit (Здоровье животных); Anti-Aging (Антивозрастная медицина); Positives Denken (Позитивное мышление); Meditation (Медитация); Freizeit (Свободное время); Wellness (Оздоровление); Krankenkasse (Медицинское страхование). Перечисленные блоки представлены в 1 или 2 изданиях.

\section{4}

Содержание блоков формируют размещенные в интернет-изданиях тексты. Их функции рассмотрены нами на примере сайтов http://www.aponet.de и http://www.apothekenumschau (всего проанализировано 184 текста). Не ставя перед собой задачу полного обзора существующей в науке дискуссии о коммуникативных функциях высказывания, приведем мнения ученых, на основе которых характеризуются функции текстов интернет-изданий в нашем исследовании.

Так, Р.О. Якобсон выделяет следующие коммуникативные функции: 1) эмотивную (экспрессивную), связанную с адресантом, выражением его отношения к тому, о чем он говорит; 2) копативную, ориентированную на оказание непосредственного воздействия на собеседника; 3 ) референтивную (денотативную, когнитивную), ориентированную на контекст (отсылка к смысловому объекту, о котором идет речь в сообщении); 4) поэтическую, проявление которой в сообщении в первую очередь наблюдается в форме текстового произведения; 5) фатическую, контактоустанавливающую; 6) метаязыковую, связанную с кодом передаваемой информации и ее правильным толкованием и пониманием собеседником [Якобсон, 1975, с. 193-200]. Каждая из данных функций связана с тем или иным участником или элементом коммуникации (подробно об этом см.: [Нурланбекова, Сеидомарова, 2015]).

Ряд исследователей дополняют приведенную классификацию магической, или заклинательной, этнической, биологической (для коммуникации животных) функциями [Леонтьев, 1968, с. 23; Мечковская, 2000, с. 3-10]. Выделяются, кроме того, познавательная, методологическая, прогностическая и практическая (инструментальная) функции [Ocновы теории коммуникации, 2003, с. 260-269]. Другие исследователи, например Ю.М. Лотман [2009], предпочитают минимизировать количество функций, выделяя лишь основные и считая другие разновидностью основных. Так, известный психолог и лингвист К. Бюлер выделял три функции языка, проявляющиеся в любом акте речи: функцию выражения (экспрессивную), функцию обращения (апеллятивную), функцию сообщения (репрезентативную) [Бюлер, 2000, с. 92-98]. Р. Димблби и Г. Бертон описывают шесть функций сообщений и коммуникативных актов: предупреждение, совет, информация, убеждение, выражение мнения, развлечение [Dimbleby, Burton, 2007, p. 101-105].

В исследуемом нами медицинском научно-популярном дискурсе высказывания (тексты) выполняют следующие коммуникативные функции: информирование, совет, предупреждение, реклама, опровержение, развлечение.

Функция информирования (в другой терминологии - репрезентативная / познавательная / референтивная) реализуется во всех текстах в рамках исследуемого материала. Однако статус этой функции может варьироваться: она может быть базовой или вспомогательной. 
Например, статья «Burn-out-Syndrom» (http://www.apotheken-umschau.de/burnout) информирует читателя о синдроме эмоциональной опустошенности, подробно описывая причины, симптомы, возможные методы диагностики и лечения заболевания (бъем текста - более 22 тысяч печатных знаков). Сведения представлены в вопросно-ответной форме, например: Was ist ein Burn-outSyndrom? (Что такое синдром эмоциональной опустошенности?) - Далее следует ответ (751 печатный знак); Ist Burn-out eine "Manager-Krankheit?" (Эмоциональная опустошенность - это болезнь руководителей?) - ответ (982 печатных знака). В заключение пользователям сайта предлагается пройти тест для определения наличия заболевания, а также приводятся контактные данные некоторых врачей, специализирующихся на лечении этого заболевания. Медицинские работники осознают последствия чтения специализированных текстов непрофессионалами, поэтому после статьи приводится обращение редакции к читателям:

Wichtiger Hinweis: Dieser Artikel enthält nur allgemeine Hinweise und darf nicht zur Selbstdiagnose oder - behandlung verwendet werden. Er kann einen Arztbesuch nicht ersetzen. Die Beantwortung individueller Fragen durch unsere Experten ist leider nicht möglich. - Важно: Данная статья содержит лишь общие сведения и не может быть использована для самодиагностики и самолечения. Она не заменяет поход к врачу. Наши эксперты, к сожалению, не смогут ответить на индивидуальные вопросы.

В статье «Was bei Schwindel hilft» (http:// www. apotheken-umschau.de/Schwindel/Wasbei-Schwindel-hilft-523707.html) подробно pacсказывается о причинах возникновения, а также о возможностях самостоятельного и профессионального лечения головокружений. Следовательно, в качестве базовой здесь выступает функция информирования, способствующая реализации интенции автора транслировать аудитории сведения о болезни. Вспомогательной является функция совета, или рекомендации: Damit das Leiden rasch und folgenlos ausheilt, rät Helmchen, frühzeitig mit Krankengymnastik zu beginnen. - Для того чтобы болезнь отступила быстро и без по- следствий, Хельмхен рекомендует своевременно начинать делать лечебную гимнастику (здесь и далее перевод наш. - H. Ш., E. $Ш$.). Лексическими маркерами реализации функции совета служат лексические единицы helfen (помогать), raten (советовать), empfehlen (рекомендовать), heilen (лечить), ausheilen (вылечивать), komplikationslos (без осложнений), folgenlos (без последствий), frühzeitig (преждевременно), rechtzeitig (своевременно).

Основная цель медицинских интернет-изданий - помочь читателям диагностировать болезнь на ранней стадии и оказать содействие в проведении профилактических мероприятий. В связи с этим более половины статей (97 из 184 , что составляет $53 \%$ ) реализуют в качестве базовых функций предупреждение и совет. Информирование при этом выступает вспомогательной функцией. Так, в статье «Prävention: Suizid im Vorfeld verhindern» (http:// www.apotheken-umschau.de/Psyche/PraeventionSuizid-im-Vorfeld-verhindern-465847.html) акцент сделан на том, как своевременно распознать такое психологическое заболевание, как депрессия, и предотвратить попытки суицида: Versuchen Sie, professionelle Hilfe hinzuzuziehen! Versuchen Sie sich nicht als Therapeut, sondern unterstützen Sie den Betroffenen, professionelle Hilfe zu suchen. Dies kann ein Arzt, ein Psychotherapeut oder eine Klinik sein. - Постарайтесь обеспечить наличие профессиональной помощи! Не пытайтесь лечить самостоятельно, окажите содействие больному в поиске профессиональной помощи. Это может быть врач, психотерапевт или клиника.

Для функций предупреждения и совета характерны формы повелительного наклонения (Versuchen Sie...), языковые единицы, выражающие модальные значения возможности и необходимости (Dies kann...).

В современном мире в сфере медицины и здоровья ежедневно появляются новинки, которые обретают спрос благодаря рекламе. Рекламную функцию в интернет-изданиях реализуют баннеры и часто сами тексты статей. Информирование здесь является вспомогательной функцией. Например, в статье "Antidepressiva: Mehr Schlaf verbessert Wirkung» (http://www.aponet.de/aktuelles/ 
Н.Л. Шамне, Е.В. Шишкина. Научно-популярные медицинские интернет-издания на немецком языке

forschung/20160912-antidepressiva-mehr-schlafverbessert-wirkung.html) рассказывается о лечении депрессии, подтверждается положительное влияние препарата Fluoxetin, дается активная ссылка на приобретение медикамента через сайт: Der Wirkstoff Fluoxetin schlug bei Studienteilnehmern, die nach Therapiebeginn zwei Wochen lang jede Nacht volle acht Stunden schliefen, deutlich besser an. - Препарат Fluoxetin принимался участниками исследования, которые уже через две недели после начала лечения спали восемь часов подряд каждую ночь.

Однако так ли хороши некоторые лечебные средства и методики в действительности? Целью многих статей является развенчивание рекламных обещаний и установление объективной истины (функция опровержения). Например, заметка «Noni: Was kann die Superfrucht?» (http://www.apotheken-umschau. de/Ernaehrung/Noni-Was-kann-die-Superfrucht524229.html) разоблачает репутацию экзотического дорогостоящего плода, нивелируя его свойства. Информирование в этом материале реализуется как вспомогательная функция: Noni-Saft ist verhältnismäßig teuer, schmeckt nicht, vollbringt keine Wunder, schadet wohl aber auch nicht. - Сок плодов нони относительно дорогой, невкусный, не оказывает чудодейственного эффекта, однако не вреден.

Решая задачу привлечения читателей к серьезному научному материалу, большинство исследуемых нами интернет-изданий (90 \%) публикуют доступные викторины, кроссворды, шарады, тесты с целью заинтересовать получателя информации и продлить время пребывания на сайте. Такие материалы выполняют, прежде всего, развлекательную функцию, информирующая функция становится вспомогательной.

В ходе исследования нами была охарактеризована структура научно-популярных медицинских интернет-изданий на немецком языке, которая формируется функциональнотематическими блоками. На основе количественных подсчетов в качестве общих для всех изданий определены функционально-тематические блоки Ernährung (Питание),
Gesundheit (Здоровье), Sport (Спорт)/ Bewegung (Движение) / Körper (Тело) / Fitness (Фитнес), Psyche (Психика), Krankheiten (Заболевания). Кроме того, выявлены уникальные блоки, входящие в структуру 1 или 2 изданий.

Установлен набор функций, реализуемых текстами научно-популярного медицинского дискурса: информирование, совет, предупреждение, реклама, опровержение, развлечение. Доказано, что функция информирования реализуется всеми статьями в рамках изучаемого дискурса, однако ее роль (базовая или вспомогательная) вариабельна и зависит от целевых установок текста.

\section{ПРИМЕЧАНИЯ}

${ }^{1}$ Cм.: «Aponet.de», «Apotheken Kurier», «Apotheken Medien GmbH \& Co. KG», «Apotheken Umschau», «Ausgeglichenes Leben - Anleitungen fürs Wohlbefinden», «Benyoo», «E-Health-Care», «Fachverlag für Gesundheitswissen», «Fit Gesund Schön», «Gesumag.de», «Gesund \& Vital Magazin», «Gesunde Medizin», «Gesundheit aktuell», «Gesundheit und Wissenschaft», «Gesundheitsblock», «Gesundheitsfocus», «Gesundheitsthema», «Gesunex - aktiv gesund leben», «Gute Pillen - Schlechte Pillen», «Kaleidoscope Gesundheitsnachrichten», «Kompass Gesundheit, das Magazin für Baden-Württemberg», «Mabuse Verlag», «Medizin Aspekte», «Medizin Compact», «Medizin-Welt: Gesund durch Wissen», «Neue Apotheken Illustrierte», «Patienten-Bibliothek», «Patric Heizmann Blog», «Ratgeber Wellness und Gesundheit», «RatgeberGesund.de», «Rechtsdepesche für das Gesundheitswesen», «Redspa Media GmbH», «Reformhaus Kurier», « «Spektrum Medizin», «Suchthilfe-Magazin», «TABU», «Topfit», «Vigo», «Die Welt der medizinischen Blogs», «Ärztezeitung».

${ }^{2}$ В научной литературе представлены и другие трактовки этого термина (см., например: [Брежнева, 2011]).

\section{СПИСОК ЛИТЕРАТУРЫ}

Ахнина, К. В. Сетевой медицинский дискурс: сущность, признаки, структура / К. В. Ахнина, В. Б. Куриленко // Вестник Российского университета дружбы народов. Серия «Вопросы образования: языки и специальность». - 2015. - № 1. - С. 76-84.

Ахнина, К. В. Сетевой медицинский дискурс: языковые и коммуникативно-прагматические характеристики : дис. ... канд. филол. наук / Ахнина Кристина Валерьевна. - М., 2016. - 211 с. 
Брежнева, Д. Д. Функционально-тематические блоки кинорецензии (на материале британской прессы) / Д. Д. Брежнева // Вестник Московского государственного областного университета. Серия «Лингвистика». - 2011. - № 6. - С. 23-29.

Бюлер, К. Теория языка. Репрезентативная функция языка / К. Бюлер. - М. : Прогресс, 2000. - 501 с.

Гагарина, Е. Ю. Коммуникативное поведение языковой личности виртуального врача в медицинском интернет-форуме : дис. ... канд. филол. наук / Гагарина Елена Юрьевна. - Астрахань, 2016. - 170 с.

Леонтьев, А. А. Общественные функции языка и его функциональные эквиваленты : (Язык и общество) / А. А. Леонтьев. - М. : Просвещение, 1968. $-153 \mathrm{c}$.

Лотман, Ю. М. О трех функциях текста / Ю. М. Лотман ; под ред. В. К. Кантора. - М. : РОССПЭН, 2009. - 399 с.

Макушева, Ж. Н. Специфика медицинского дискурса на материале аутентичных текстов по специальности / Ж. Н. Макушева, М.Б.Ковалева // Филологические науки. Вопросы теории и практики. 2014. - № 5 (35), ч. 1. - С. 108-111.

Мечковская, Н. Б. Социальная лингвистика / Н. Б. Мечковская. - 2-е изд., испр. - М. : Аспект Пресс, 2000. - 207 c.

Нурланбекова, Е. К. Коммуникативный процесс и функции языка / Е. К. Нурланбекова, С. Н. Сеидомарова // Международный журнал прикладных и фундаментальных исследований. - 2015. - № 2, ч. 2. - С. 307-311.

Основы теории коммуникации / под ред. проф. М. А. Василика. - М. : Гардарики, 2003. $615 \mathrm{c}$.

Якобсон, Р. О. Лингвистика и поэтика / Р. О. Якобсон // Структурализм: «за» и «против» : сб. ст. - М. : Прогресс, 1975. - С. 193-230.

Dimbleby, R. More than words / R. Dimbleby, G. Burton. - London : Routledge, 2007. - 283 p.

\section{REFERENCES}

Akhnina K.V., Kurilenko V.B. Setevoy meditsinskiy diskurs: sushchnost, priznaki, struktura [Network Medical Discourse: Essence, Signs, Structure]. Vestnik Rossiyskogo universiteta druzhby narodov. Seriya «Voprosy obrazovaniya: yazyki $i$ spetsialnost», 2015, no. 1, pp. 76-84.

Akhnina K.V. Setevoy meditsinskiy diskurs: yazykovye i kommunikativno-pragmaticheskie kharakteristiki: dis. ... kand. filol. nauk [Network
Medical Discourse: Linguistic and CommunicativePragmatical Characteristics. Cand. philol. sci. diss.]. Moscow, 2016. $211 \mathrm{p}$.

Brezhneva D.D. Funktsionalno-tematicheskie bloki kinoretsenzii (na materiale britanskoy pressy) [Functional and Thematic Units of Film Review (Based on the British Press)]. Vestnik Moskovskogo gosudarstvennogo oblastnogo universiteta. Seriya «Lingvistika», 2011, no. 6, pp. 23-29.

Buller K. Teoriya yazyka. Reprezentativnaya funktsiya yazyka [Language Theory. Representative Function of Language]. Moscow, Progress Publ., 2000. $501 \mathrm{p}$.

Gagarina E.Yu. Kommunikativnoe povedenie yazykovoy lichnosti virtualnogo vracha $v$ meditsinskom internet-forume: dis. ... kand. filol. nauk [Communicative Behavior of the Linguistic Personality of a Virtual Doctor in a Medical Internet Forum. Cand. philol. sci. diss.]. Moscow, 2016. 170 p.

Leontyev A.A. Obshchestvennye funktsii yazyka i ego funktsionalnye ekvivalenty: (Yazyk $i$ obshchestvo) [Social Functions of Language and Its Functional Equivalents: (Language and Society)]. Moscow, Prosveshchenie Publ., 1968. 153 p.

Lotman Yu.M. O trekh funktsiyakh teksta [The Three Functions of the Text]. Moscow, ROSSPEN Publ., 2009. 399 p.

Makusheva Zh.N., Kovaleva M.B. Spetsifika meditsinskogo diskursa na materiale autentichnykh tekstov po spetsialnosti [Specificity of Medical Discourse on the Material of Authentic Special Texts]. Filologicheskie nauki. Voprosy teorii i praktiki, 2014, no. 5(35), part 1, pp. 108-111.

Mechkovskaya N.B. Sotsialnaya lingvistika [Social Linguistics]. $2^{\text {nd }}$ ed. Moscow, Aspekt Press Publ., 2000. 207 p.

Nurlanbekova E.K., Seidomarova S.N. Kommunikativnyy protsess i funktsii yazyka [Communication Process and Language Functions]. Mezhdunarodnyy zhurnal prikladnykh $i$ fundamentalnykh issledovaniy, 2015, no. 2, part 2, pp. 307-311.

Vasilik M.A., ed. Osnovy teorii kommunikatsii [Basics of Communication Theory]. Moscow, Gardariki Publ, 2003. $615 \mathrm{p}$.

Jakobson R.O. Lingvistika i poetika [Linguistics and Poetics]. Strukturalizm: "za" $i$ "protiv": sbornik statey [Structuralism: "for" and "against": Collection of Articles]. Moscow, Progress Publ., 1975, pp. 193230.

Dimbleby R., Burton G. More Than Words. London, Routledge, 2007.283 p. 
Н.Л. Шамне, Е.В. Шишкина. Научно-популярные медицинские интернет-издания на немецком языке

\section{Information About the Authors}

Nikolay L. Shamne, Doctor of Sciences (Philology), Professor, Head of the Institute of Philology and Intercultural Communication, Volgograd State University, Prosp. Universitetsky, 100, 400062 Volgograd, Russian Federation, nikolay.shamne@volsu.ru, http://orcid.org/0000-0002-5745-8907.

Ekaterina V. Shishkina, Candidate of Sciences (Philology), Senior Lecturer, Department of Foreign Languages with the Latin Course, Volgograd State Medical University, Sq. Pavshikh Bortsov, 1, 400131 Volgograd, Russian Federation, e.w.shishkina@gmail.com, http://orcid.org/0000-0001-8620-8387.

\section{Информация об авторах}

Николай Леонидович Шамне, доктор филологических наук, профессор, директор института филологии и межкультурной коммуникации, Волгоградский государственный университет, просп. Университетский, 100, 400062 г. Волгоград, Российская Федерация, nikolay.shamne@volsu.ru, http://orcid.org/0000-0002-5745-8907.

Екатерина Викторовна Шишкина, кандидат филологических наук, старший преподаватель кафедры иностранных языков с курсом латинского языка, Волгоградский государственный медицинский университет, пл. Павших Борцов, 1, 400131 г. Волгоград, Российская Федерация, e.w.shishkina@gmail.com,http://orcid.org/0000-0001-8620-8387. 